\title{
Educating Radiologists About Pain
}

\author{
Richard B. Gunderman, MD PhD
}

Brian D. Fogler, BS

Indiana University School of Medicine, 702 North Barnhill Drive, Room 1053, Indianapolis, IN 46202

Key Words: Pain; pain assessment; pain management; radiologists; education

It is vital that radiologists understand pain. After all, it is the most common symptom that leads patients to seek medical care, and represents one of the most common indications for diagnostic and interventional radiological procedures 1, 2 and 3. In addition, radiological procedures can be a source of pain to patients, particularly in the context of interventional procedures ${ }^{4}$ and ${ }^{5}$. By gaining a better understanding of the nature, assessment, and effective management of pain, radiologists and radiology personnel can do a better job of caring for patients.

Nature of Pain

Pain is an unpleasant subjective sensation, although its precise definition remains elusive. It can be caused by a variety of noxious stimuli, such as mechanical trauma, temperature extremes, and a variety of chemicals. These types of pain are usually associated with the activation of nociceptors (pain receptors) in the peripheral nervous system. Depending on the type of nociceptor involved, pain may be experienced as sharp and focal, as in the puncture of a fingertip, or dull and diffuse, as in the stretching or inflammation of the bowel (6).

Other types of pain are more difficult to understand. In some cases, pain may also be traced to a disorder of the nervous system itself, such as the neuropathic pain associated with long-standing diabetes (7). "Phantom limb” pain, pain felt in a limb or part of the body that is no longer present, is experienced

This is the author's manuscript of the article published in final edited form as:

Gunderman, R. B., \& Fogler, B. D. (2016). Educating Radiologists About Pain. Academic Radiology, 23(8), 10641066. https://doi.org/10.1016/j.acra.2016.02.020 
by the majority of amputees, at least for a time (8). Psychology plays a key role in the pain experience. In many cases of chest pain, headaches, and back pain, no anatomic or pathologic cause of pain can be identified (9).

During the 17th century, French philosopher Rene Descartes proposed that pain represents the transmission of a disturbance from injured tissue to the brain (10). Today the broad outlines of the pathways along which sensations that register as pain are transmitted are relatively well worked out. From the stimulation of a sensory receptor that can generate a pain "signal," the impulse travels to the spinal cord, crosses in the anterior commissure, ascends via the spinothalamic tract through a nucleus in the thalamus, and then travels into fibers that terminate predominately in the primary and secondary somatosensory cortex, as well as in portions of the brainstem, limbic system, and other areas of the cerebral cortex (11).

Yet this account does not fully explain the nature of certain types of pain, such as many cases of low back pain, chronic pain, and phantom limb pain. To further explain the complexity of pain, additional theories have built on the theory proposed by Descartes. These include gate control theory, the descending pain modulatory system, and the neuromatrix theory. These more recent theories incorporate higher brain processes in understanding the pain experience 10 and 11.

Although pain is by definition aversive, the inability to feel pain poses a serious problem for those afflicted with it. Congenital insensitivity to pain is associated with a dramatically increased risk of injury to organs, including the eyes, tongue, and extremities, as well as a general reduction in life expectancy 12 and 13. Other forms of insensitivity to pain are acquired, such as long-standing diabetes and spinal cord injury, and these too are associated with an increased risk of injury 14 and 15.

Insensitivity to pain serves as a reminder of its adaptive value. A familiar example at the reflexive level is the withdrawal of a finger from a hot plate. In other cases, such withdrawal is a learned response, such as the child who learns to avoid bees after suffering a sting. Based on the hypothesis that pain is an 
adaptive response to promote survival, it is no surprise that the most severe forms of pain are often associated with potentially disabling and lethal forms of injury. Yet many instances of pain seem to serve no biologically beneficial purpose, yet seriously undermine quality of life.

\section{Assessment of Pain}

For generations, physicians have been trained to assess pain according to a number of parameters. A mnemonic device for recalling such parameters is SOCRATES, which stands for Site, Onset, Character, Radiation, Associations, Time course, Exacerbating/relieving factors, and Severity (16). These parameters are quite helpful in assessing disease processes such as appendicitis. Early in appendicitis, when inflammation is confined to the appendix, the pain starts out periumbilical and diffuse, but as inflammation spreads to the peritoneum, it becomes more focal and localized to the right lower quadrant (17). Through assessing these parameters, physicians can optimize the effectiveness and efficiency of the diagnostic workup.

Since 2001, the Joint Commission, which accredits hospitals and health-care organizations, has mandated the regular assessment of pain, often linked to a movement to establish pain as the "fifth vital sign” (18). The problem with calling pain a vital sign, of course, is that, in contrast to pulse, respiration, temperature, and blood pressure, it is often difficult or impossible to assess objectively. A physician or other health professional often cannot independently assess the character or severity of pain or even determine with certainty that it is present.

Efforts to move the assessment of pain from the realm of the subjective into the objective have, naturally, tended to focus on quantification, the central parameter of all other vital signs. The scale most often used is the Numeric Rating Scale. Patients are asked to rate their pain on a $0-10$ scale, 0 being the absence of pain and 10 corresponding to the worst pain the patient has ever known (18). More recently, such scales have been adapted to patients who are too young or illiterate by replacing the numerical scale with a range of facial expressions depicting increasing levels of discomfort (19). 
One difficulty in assessing pain is the fact that different people often report different levels of pain and difficulty coping with a common source of pain, depending on a variety of factors. For example, athletes in competition and women in labor may experience severe pain, yet report that they are able to bear it in pursuit of a desired outcome. Pain may also be underreported in connection with fear that it would lead to loss of respect, stigmatization, and loss of opportunities (20). Others view pain as a necessary and expected part of their culture or religion 3 and 20. An environment of respect and trust is important in helping patients describe their pain honestly.

In other circumstances, pain may be overreported and exaggerated. One well-known example is the so-called “drug-seeking” patient, who may seek to obtain pain relievers to manage an addiction or as a means of making money (21). Other reasons to falsely report pain or exaggerate its severity include the so-called secondary gains, such as days off school or work, decreased responsibilities in such settings, or to gain sympathy (22).

Fueled by recent increases in the rates of opioid dependency and the increasing numbers of deaths associated with opioid use, some physicians have begun to question whether assessments of pain intensity, even if completely accurate, constitute a valid marker by which to titrate dosage schedules. Especially in the setting of chronic pain, other factors such as close interpersonal relationships, a strong sense of purpose in life, and a clear understanding of both the source of pain and what is being done to correct its source may play an equal or even more important role.

\section{Management}

As in other areas of medicine, attitudes toward pain have shifted in recent decades. Some physicians and pharmaceutical firms began arguing around 1990 that American medicine was systematically under-recognizing, under-assessing, and under-treating pain 23 and 24 . This fueled the dramatic increase in the use of opioids and other pain relievers. In the last few years, the tide has begun to 
reverse, with a number of pain experts arguing that opioids have been overprescribed, to the point that the misuse of prescription opioids now substantially exceeds illicit drugs as a cause of death 25, 26 and 27.

Of course, opioids, are not the only class of drugs that can be used to treat pain. Other options include nonsteroidal anti-inflammatory drugs, which are generally useful in treating pain associated with inflammation as well as fever. Acetaminophen can increase pain tolerance, but has little effect on inflammation (28). Muscle relaxants may have a role in patients with pain due to muscle tension, such as low back pain (29). Antianxiety drugs not only reduce anxiety but may also promote both relaxation and enhanced coping. The same can be said for antidepressants, at least in some cases. Others include gabapentin and pregabalin, which have shown efficacy in treating neuropathic pain (28).

The side effects of pain medications, and particularly the problems associated with opioids, are fueling an increased level of interest in non-pharmacologic approaches to pain management. For example, individuals who have strong relationships, including family, friends, and colleagues, often require less pain relief than individuals without social support. This is one reason that having family and friends nearby can make a big difference in how patients experience pain before, during, and after tissue injury.

A powerful technique for reducing pain is often called distraction, but perhaps a better term would be shifting the patient's focus of attention. For example, performing a task or participating in an activity, while not directly addressing the pain, can often decrease the burden associated with it. Interventions during radiological procedures that can decrease pain through this technique include having the patient count, talking about something other than the procedure, playing videogames and virtual reality, and asking the patient to repeat a positive statement (30).

An additional technique for reducing pain in radiological procedures is giving the control of the procedure to the patient (9). In one study, women in active labor were given control over parts of the delivery process, and positive effects were seen in terms of reducing pain and fatigue, and increasing 
energy (31). By giving patients some measure of control over the procedure, such as which side of the abdomen a paracentesis is performed on, they often report less pain and cope better with it.

The power of suggestion should not be underestimated. For example, when patients believe they are receiving a pain-relieving medication, a substantial percentage will experience at least some measure of relief, even though the pill or injection is just a placebo (32). This phenomenon has not been fully explained, but one factor is the reduction in anxiety associated with the belief that steps are being taken to prevent or relieve pain (33).

Other approaches, often considered part of complementary and alternative medicine, may also be effective. For example, hypnosis has been demonstrated to be effective in relieving the pain associated with surgical and needle-related procedures 30 and 34. Some studies have suggested a role for acupuncture, but as yet no firm evidence is at hand (35). Other studies have suggested music can reduce pain and anxiety; however, no conclusive evidence exists at this time (36). Spinal manipulation associated with chiropractic treatment may produce some benefit, but it does not appear to exceed that available through other more conventional means, including exercise and muscle-strengthening exercises (37).

In sum, pain, the most common presenting complaint in most emergency departments, is a complex problem that defies simple solution (1). In general, radiologists need to be attuned to pain, preventing and relieving it to the extent possible, but also bearing in mind that there is no one-size-fits-all approach. In some cases, attempts to relieve pain may produce more harm than benefit. One thing, however, is certain—by responding effectively to pain, all health professionals can build more trusting and compassionate relationships with patients. 


\section{References}

1. Tanabe P, Buschmann M. A prospective study of ED pain management practices and the patient's perspective. J Emerg Nurs 1999; 25:171-177.

2. Zondervan RL, Hahn PF, Sadow CA, et al. Body CT scanning in young adults: examination indications, patient outcomes, and risk of radiationinduced cancer. Radiology 2013; 267:460-469.

3. Notcutt W, Gibbs G. Inadequate pain management: myth, stigma and professional fear. Postgrad Med J 2010; 86:453-458.

4. Zhou B, Wang J, Yan Z, et al. Liver cancer: effects, safety, and costeffectiveness of controlled-release oxycodone for pain control after TACE. Radiology 2012; 262:1014-1021.

5. Zhao JB, Luo ZL, Feng C, et al. Effects of the intermittent injection with super-low pressure on the postoperative pain control during the uterine artery embolization for uterine myoma. Int J Clin Exp Med 2015; 8:14303-14307.

6. Ropper AH, Samuels MA, Klein JP. Pain. In: Adams and Victor's principles of neurology. 10th ed. New York, NY: The McGraw-Hill Companies, 2014; Chapter 8.

7. Jensen TS, Gottrup H, Sindrup SH, et al. The clinical picture of neuropathic pain. Eur J Pharmacol 2001; 429:1-11.

8. Flor H, Nikolajsen L, Staehelin Jensen T. Phantom limb pain: a case of maladaptive CNS plasticity? Nat Rev Neurosci 2006; 7:873-881.

9. Eccleston C. Role of psychology in pain management. Br J Anaesth 2001; 87:144-152.

10. Melzack R. Pain: past, present and future. Can J Exp Psychol 1993; 47:615-629.

11. Bourne S, Machado AG, Nagel SJ. Basic anatomy and physiology of pain pathways. Neurosurg Clin N Am 2014; 25:629-638. 
12. Nagasako EM, Oaklander AL, Dworkin RH. Congenital insensitivity to pain: an update. Pain 2003; 101:213-219.

13. Golshani AE, Kamdar AA, Spence SC, et al. Congenital indifference to pain: an illustrated case report and literature review. J Radiol Case Rep 2014; 8:16-23.

14. Phillips A, Mehl AA. Diabetes mellitus and the increased risk of foot injuries. J Wound Care 2015; 24(5 suppl 2):4-7.

15. McKinley WO, Jackson AB, Cardenas DD, et al. Long-term medical complications after traumatic spinal cord injury: a regional model systems analysis. Arch Phys Med Rehabil 1999; 80:1402-1410.

16. Clayton HA, Reschak GLC, Gaynor SE, et al. A novel program to assess and manage pain. Medsurg Nurs 2000; 9:318.

17. Jacobs DO. Acute appendicitis and peritonitis. In: Kasper D, Fauci A, Hauser S, et al., eds. Harrison’s principles of internal medicine. 19th ed. New York, NY: McGraw-Hill Education, 2015.

18. Lorenz KA, Sherbourne CD, Shugarman LR, et al. How reliable is pain as the fifth vital sign? J Am Board Fam Med 2009; 22:291-298.

19. Keck JF, Gerkensmeyer JE, Joyce BA, et al. Reliability and validity of the Faces and Word Descriptor Scales to measure procedural pain. J Pediatr Nurs 1996; 11:368-374.

20. Goldberg DS. Job and the stigmatization of chronic pain. Perspect Biol Med 2010; 53:425-438.

21. Bendtsen P, Hensing G, Ebeling C, et al. What are the qualities of dilemmas experienced when prescribing opioids in general practice? Pain 1999; 82:89-96.

22. Fishbain DA, Rosomoff HL, Cutler RB, et al. Secondary gain concept: a review of the scientific evidence. Clin J Pain 1995; 11:6-21.

23. Melzack R. The tragedy of needless pain. Sci Am 1990; 262:27-33. 
24. Portenoy RK, Foley KM. Chronic use of opioid analgesics in nonmalignant pain: report of 38 cases. Pain 1986; 25:171-186.

25. Compton WM, Boyle M, Wargo E. Prescription opioid abuse: problems and responses. Prev Med 2015; 80:5-9.

26. Paulozzi LJ, Weisler RH, Patkar AA. A national epidemic of unintentional prescription opioid overdose deaths: how physicians can help control it. J Clin Psychiatry 2011; 72:589-592.

27. Okie S. A flood of opioids, a rising tide of deaths. N Engl J Med 2010; 363:1981-1985.

28. Rabow MW, Pantilat SZ. Palliative care \& pain management. In: Papadakis MA, McPhee SJ, Rabow MW, eds. Current medical diagnosis \& treatment 2016. New York, NY: McGraw-Hill Education, 2016.

29. van Tulder MW, Touray T, Furlan AD, et al. Muscle relaxants for nonspecific low back pain. Cochrane Database Syst Rev 2003; (2):CD004252.

30. Uman LS, Chambers CT, McGrath PJ, et al. A systematic review of randomized controlled trials examining psychological interventions for needlerelated procedural pain and distress in children and adolescents: an abbreviated Cochrane review. J Pediatr Psychol 2008; 33:842-854.

31. Leventhal EA, Leventhal H, Shacham S, et al. Active coping reduces reports of pain from childbirth. J Consult Clin Psychol 1989; 57:365-371.

32. Puhl AA, Reinhart CJ, Rok ER, et al. An examination of the observed placebo effect associated with the treatment of low back pain—a systematic review. Pain Res Manag 2011; 16:45-52.

33. Price DD, Finniss DG, Benedetti F. A comprehensive review of the placebo effect: recent advances and current thought. Annu Rev Psychol 2008; 59:565-590.

34. Kendrick C, Sliwinski J, Yu Y, et al. Hypnosis for acute procedural pain: a critical review. Int J Clin Exp Hypn 2016; 64:75-115. 
35. Yuan J, Purepong N, Kerr DP, et al. Effectiveness of acupuncture for low back pain: a systematic review. Spine 2008; 33:E887-E900.

36. Yinger OS, Gooding LF. A systematic review of music-based interventions for procedural support. J Music Ther 2015; 52:1-77.

37. Assendelft WJ, Morton SC, Yu EI, et al. Spinal manipulative therapy for low back pain. A metaanalysis of effectiveness relative to other therapies. Ann Intern Med 2003; 138:871-881. 